\title{
EL PRIMVS CALAMVS DE JUAN DE CARAMUEL LOBKOWITZ
}

\author{
Por \\ ISABEL PARAÍSO
}

\section{Introducción}

$\int$

S un honor y una satisfacción hablar hoy de Juan de Caramuel aquí, en Sevilla, en este foro de estudiosos de Métrica cuyo órgano de expresión escrita, la revista Rhythmica, lleva precisamente el nombre de una de las partes -la más viva hoy- del tratado de Caramuel.

El Primvs Calamvs, ese monumental tratado, es el más importante de los Siglos de Oro para nuestra materia. Ocupa un lugar singular en nuestra tradición española de estudios métricos, y está rodeado de paradojas: Su importancia objetiva y su escasa difusión entre los estudiosos; la originalidad de sus puntos de vista y el carácter polémico de algunos de ellos; incluso su gestación y redacción, que abarcan la extensa vida del autor. En sus propias palabras:

Est liber, quem in pueritiâ scripsi: in adolescentiâ promovi: \& nunc in senectute elico. ${ }^{1}$

Las paradojas se nos aclaran cuando nos acercamos a la obra y a su autor.

1 Estas palabras figuran en $\S 2$ : Tabla de "OPERA OMNIA", Sección "Primvs Calamvs". Cfr. "Ioannis Caramvelis Campaniensium, \& Satrianensium Episcopi, \&c. Tomvs II. Ob ocvlos exhibens RHYTHMICAM. [...] Editio secunda,1668. 


\section{Un libro sepultado en el tiempo}

La obra culminante de la métrica española en los Siglos de Oro, el Primvs Calamvs del polígrafo madrileño Juan de Caramuel (1606-1682), resulta al mismo tiempo, como decíamos, la más misteriosa. Las ideas literarias y métricas de Caramuel son, aún hoy en día, tan atrayentes como poco conocidas. Emiliano Díez Echarri (Teorías métricas del Siglo de Oro, 1949 y 1970) escribe:

El más destacado, el más completo y acaso el menos leído de nuestros tratadistas métricos del Siglo de Oro es el Obispo don Juan de Caramuel. Menéndez Pelayo lo reputa como «el más erudito y fecundo de los polígrafos del siglo XVII» ${ }^{2}[\ldots] \mathrm{Y}$, en efecto, su cultura es asombrosa. Domina multitud de lenguas vivas y muertas, incluidos el húngaro y el chino, de lo que da frecuentes pruebas en sus escritos. Con relación al verso, nos dejó en el Primus Calamus un arsenal de noticias y datos no explotado todavía. ${ }^{3}$

Efectivamente. Más de medio siglo después de estas palabras, el Primvs Calamvs se nos muestra hoy como una obra sepultada en el tiempo. Citada elogiosamente por los pocos que se han acercado a ella, y atacada también -continuando en sordina la gran polémica que la potente personalidad de Caramuel suscitó entre sus contemporáneos-. Podríamos preguntarnos por qué ese olvido actual.

${ }^{2}$ Cfr. Historia de las Ideas Estéticas en España. (1974, 2 vols.; vol. I: 695 y 798-801). En p. 798 menciona «la voluminosa Poética que el obispo don Juan Caramuel, el más erudito y fecundo de los polígrafos del siglo XVII, publicó con el título de Primus Calamus, dividiéndola en Rhythmica y Metametrica». A continuación expone por extenso la teoría caramueliana sobre el teatro (que figura solamente en las Epístolas adicionales de la segunda edición de la Rítmica).

${ }^{3}$ Emiliano Díez Echarri (1949; 2 ${ }^{\mathrm{a}}$ ed. 1970: 87-88). 


\subsection{Razones de un olvido}

En primer lugar, el Primvs Calamvs no está traducido. Hay que leerlo en latín, lengua que -desgraciadamente- cada vez resulta más ajena a los filólogos hispánicos en los planes de estudio actuales; mientras los filólogos clásicos, que accederían sin dificultad al texto, apenas se han interesado hasta hoy por la obra. ${ }^{4}$

En segundo lugar, el Primvs Calamvs no ha sido reeditado desde el siglo XVII. No hay una edición moderna de él, ni reedición, lo que dificulta su consulta. Hay que leerla en bibliotecas para investigadores, y hacerlo en latín.

En tercer lugar, nadie ha emprendido -que sepamos nosotros- la tarea de explicar el conjunto de las ideas contenidas en este libro gigantesco. ${ }^{5}$ Hay trabajos parciales, ${ }^{6}$ pero la labor de hacer accesible la totalidad de su teoría literaria y teoría métrica sigue esperando a un investigador paciente.

Estas dificultades para leer el Primvs Calamvs directamente en español van a ser felizmente subsanadas en breve: La parte más interesante de la obra, el tomo II: Rhythmica, ha sido traducido y será publicado pronto en la Universidad de Valladolid, bajo la dirección de quien esto escribe. Gracias a la generosidad de un equipo de profesores de Filología Latina y a dos profesoras de Teoría de Literatura, y gracias también al mecenazgo de tres Universidades (UNED, Murcia y Valladolid), la Rítmica de Caramuel está próxima a ver la luz.

${ }^{4}$ Una honrosa excepción la constituye el profesor mejicano Héctor Hernández Nieto, doctor en Filología Clásica y también en Filología Hispánica. Creemos que hoy en día es el mayor especialista en el campo que nos ocupa.

${ }^{5}$ El profesor Hernández Nieto ha comenzado a hacerlo, sintetizando las ideas literarias de las Epístolas que anteceden y siguen al cuerpo doctrinal en las dos ediciones de la Rhythmica. Lo hace en su libro Las ideas literarias de Caramuel (1992), y en diversos artículos.

${ }^{6}$ E. Díez Echarri (1949 y 1970) sigue siendo quien más sistemáticamente ha expuesto los principales puntos de su teoría métrica. Trabajos más recientes, pero referentes a algún tema concreto, son los de Déborah Dietrick (de próxima aparición) e Isabel Paraíso (id.). 


\subsection{Interés actual por la figura y la obra de Caramuel}

Aunque las teorías literarias y métricas de Caramuel se encuentran en ese estado de semiolvido que acabamos de expresar, no sucede lo mismo con su persona y con su obra en otros campos. En las últimas décadas, el hombre $-\mathrm{y}$ sobre todo sus escritos- están atrayendo el interés de diversos investigadores en Italia, Alemania y España.

Así en 1982 se celebró en Vigevano (Lombardía, cerca de Milán) - lugar donde pasó Caramuel sus últimos años como obispo y donde murió-, un Congreso Internacional con motivo del tercer centenario de su fallecimiento. ${ }^{7}$ Por otra parte, se han realizado ediciones actuales, o reediciones, de algunos libros de Caramuel. P. ej., se ha traducido su Gramática audaz, y reeditado su Procursor Logicus complectens Grammaticam Audacem; 8 se ha realizado una edición facsímil del magnífico libro Arquitectura civil recta y oblicua, en 3 volúmenes;' se ha reeditado la Meditatio Promialis, con el título de Filosofía de la Matemática $;{ }^{10}$ e igualmente se han reeditado sus Laberintos. ${ }^{11}$ Este mismo año (2004) ha sido traducido y editado su Syntagma de Arte Typographica. ${ }^{12}$

La gigantesca obra de Caramuel -cuyos hitos se encuentran en campos tan dispares como la Matemática, la Teología, la Filosofía, la Gramática, la Astronomía, la Arquitectura y la Músicaestá siendo objeto de atención, revalorización y estudio. Así los trabajos de Nicolás Borrego Hernández desde la Historia de la Lógica. ${ }^{13}$ La Universidad de Valladolid centra una parte de esta atención: el profesor Maximiliano Fartos Martínez dedica un capítulo a Caramuel en La filosofía española en Castilla y León, ${ }^{14}$

\footnotetext{
${ }^{7}$ Cfr. Alberto Porqueras Mayo: "Prólogo" al citado libro de Héctor Hernández Nieto (1992).

${ }^{8}$ Gramática audaz. Trad. de Pedro Arias; estudio preliminar de Lorenzo Velázquez. (2000). Prcecursor Logicus complectens Grammaticam Audacem (1989).

${ }^{9}$ Estudio preliminar de Antonio Bonet Correa (1984).

${ }^{10}$ Estudio preliminar y traducción de Juan Velarde Lombraña (1989).

${ }^{11}$ Ed. de Víctor Infantes (1981).

${ }^{12}$ Traducción y edición de Pablo Andrés Escapa. Salamanca (2004).

13 “Aportaciones de Caramuel a la lógica teórica" (1992: 363-399), y "La lógica oblicua de Caramuel” (1992: 298).

14 1997: 503-511.
} 
y el profesor José María López Piñero, desde la Historia de la Ciencia defiende el "europeísmo" de Caramuel. ${ }^{15}$

La vida de Caramuel, más fascinante que una novela de aventuras, ha sido objeto de un bien documentado libro. ${ }^{16}$ En resumen, fue «monje $[. .$.$] escritor, polemista, diplomático, misionero, de-$ fensor de la fe y con fe sospechosa y, por último, pastor solícito de su grey»». ${ }^{17}$ Sus contemporáneos lo alaban hasta proclamarlo casi divino, o bien lo atacan durísimamente - los jansenistas sobre todo- e intentan llevarlo ante el tribunal de la Inquisición (1652): sus coetáneos se dividen claramente en caramuelistas y anticaramuelistas.

De padres extranjeros al servicio de los Austrias, ${ }^{18}$ Juan de Caramuel Lobkowitz nació en Madrid (1606) y siempre se sintió orgulloso de ser español. ${ }^{19}$ Estudió Humanidades y Filosofía en la Universidad de Alcalá. Ingresó en la Orden Cisterciense, realizando sus votos en el Monasterio de la Santa Espina (Valladolid, entonces perteneciente a la diócesis de Palencia). Impartió al principio clases en colegios de su orden en Alcalá de Henares y en Palazuelos (Valladolid).

Después ocupó varios puestos eclesiásticos en diversos lugares europeos, como los Países Bajos (Flandes), Alemania (Palatinado inferior), Bohemia y Viena. Se enfrentó dialécticamente, de modo oral y escrito, con los jansenistas belgas y con los protestantes alemanes. Defendió militarmente algunas ciudades cercadas por los franceses o por los suecos -entre ellas Praga, en 1648-, obteniendo victorias para la Cancillería de la Corte en Viena, con los emperadores austríacos Fernando III y Leopoldo I de Habsburgo, parientes y aliados de España, gobernada aquellos años por Felipe IV (1621-1665), y después por Carlos II (1665-1700).

15 1979: 436-437.

${ }^{16}$ Julián Velarde Lombraña: Juan Caramuel. Vida y obra (1989). Tiene muy en cuenta el mejor de sus biógrafos anteriores: Jacopo Antonio Tadisi (1760).

${ }^{17}$ H. Hernández Nieto (1992: 25).

${ }^{18}$ Según el propio Caramuel: «matre Bohema et patre Lutzenburgensi natum». (Carta a Pierre Gassendi, 25-I-1645).

${ }^{19}$ Lo expresa en numerosos lugares de sus obras. Por ejemplo: Metametrica, I, 4 (§ 89) «ego, magno Dei beneficio, in Hispania sum natus». 
Mantuvo correspondencia con los mayores intelectuales de Europa. Reformó el canto gregoriano. Estuvo a punto de ser procesado por la Inquisición, y a punto también de ser elegido Cardenal. Planeó y dirigió la construcción de la fachada de la catedral de Vigevano, con el fin de dar armonía a la plaza donde se ubica. Allí falleció en 1682. ${ }^{20}$

Ésta es, a grandes rasgos, su vida.

\section{Estructura del Primvs Calamvs}

\subsection{Estructura externa}

Aparece el Primvs Calamvs dividido en dos ediciones distintas: La Metametrica, en 2 vols. (1663), ${ }^{21}$ y la Rhythmica, en uno (1665 y 1668). ${ }^{22}$

${ }^{20}$ La fama de Caramuel era tan grande, que cuando falleció en Italia se celebraron funerales solemnes en muchas Universidades europeas: Salamanca, Lovaina, Coimbra, Alcalá, París, Baeza, Granada y en el Colegio Mayor de Sevilla. En la catedral de Viena hubo también solemnes exequias, con asistencia del emperador Leopoldo y su corte. En la puerta exterior de la catedral de Viena se colocó un cuadro con esta inscripción: «Ante cadet mundus / quam surgat Caramuel secundus». (Cfr. J. Velarde Lombraña, 1989: 376).

${ }^{21}$ La primera página de ambos volúmenes indican, respectivamente:

I. Ioannis Caramvelis, PRIMVS CALAMVS ob oculos ponens METAMETRICAM, qvæ variis Currentium, Recurrentium, Ascendentium, Descendentium, nec-non Circumvolantium Versuum Ductibus, vt æri incisos, avt buxo inscvlptos, aut plvmbo infvsos, multiformes LABYRINTHOS exornat.

Fabivs Falconivs excudebat Anno MDCLXIII.

Superiorum Consensu.

II. Ioannis Caramvelis, PRIMVS CALAMVS Secundam Partem METAMETRICÆ exhibens.

(En la portada del primer tomo aparece la palabra "Metamétrica" con caracteres griegos: Ioannis Caramvelis Primvs CALAMVS METAMETRIKHN exhibens. Romæ Anno MDCLXII").

${ }^{22}$ La primera página del volumen reza:

«Ioannis Caramvelis PRIMVS CALAMVS. Tomvs II, ob oculos exhibens RYTHMICAM, quæ Hispanicos, Italicos, Gallicos, Germanicos, \&c. Versus metitur, eosdemq; Concentu exornans, viam aperit ut Orientales possint Populi conformare, aut etiam reformare proprios Numeros.

Apud Sanctvm Angelvm della Fratta, Ex Typographia Episcopali Satrianensi. M.DC.LXV.

Svperiorvm Permissv».

La edición de 1668, llamada “segunda edición" pero en realidad reedición 
1) La edición de la Metametrica está fechada en Roma, realizada por Fabio Falconio en 1663. ${ }^{23}$ Son 2 volúmenes, con 835 páginas. ${ }^{24}$

2) La edición de la Rhythmica, en Santo Angelo della Fratta, editada por la Tipografía Episcopal Satrianense, data de 1665 y $1668 .{ }^{25}$ La de 1665 es un volumen de 586 páginas, más 8 iniciales no numeradas. La de 1668 es una reedición de esta obra -utiliza, en la parte central, que contiene la doctrina métrica, exactamente las mismas planchas de la primera edición, incluso con la misma numeración de páginas-. Por el contrario, en lo que precede y sigue al cuerpo doctrinal, presenta varios índices añadidos y más epístolas finales. Es un volumen de 741 páginas, más XLVIII iniciales, paginadas con números romanos. ${ }^{26}$

idéntica del corpus doctrinal, al que se le añaden índices iniciales y epístolas finales, dice así:

«Ioannis Caramvelis PRIMVS CALAMVS, Tomvs II, ob ocvlos exhibens RHYTHMICAM, qvæ Hispanicos, Italicos, Gallicos, Germanicos, \&c. Versus metitur, eosdemque Concentu exornans, viam aperit, ut Orientales possint Populi (Hebræi, Arabes, Turcici, Persici, Indici, Sinenses, Iaponici, \&c.) conformare, aut etiam reformare proprios Numeros.

EDITIO SECVNDA. / Duplo auctior./ Diversis, iisque necessariis Indicibus locupletata.

Campaniæ, Ex Officina Episcopali, 1668. Superiorum permissu».

${ }^{23}$ Las dificultades -incluso formales- de este libro comienzan ya en la primera página. Hay una contradicción entre la portada, que señala la fecha de 1662 ("Romæ, Anno MDCLXII") y la primera página, que indica 1663 ("Romæ, Fabius Falconius excudebat Anno MDCLXIII"). Consideraremos como fecha definitiva esta última, interpretando que la primera, muy elaborada, responde a la fecha en que el artista realizó la portada.

${ }^{24}$ Segunda dificultad formal: Los dos volúmenes que integran la Metamétrica no están paginados con "numerus cursus". Cada parte de las muchas que integran ambos tomos lleva su propia paginación independiente. Nosotros hemos paginado los dos volúmenes con número corrido, lo que da un total de 835 páginas.

La numeración de los epígrafes que aparecen en el libro, en cambio, es totalmente fiable. Por ello, si tenemos que referirnos a alguna cita o parte de la Metamétrica, daremos entre paréntesis el número del epígrafe.

${ }^{25}$ En ambos casos es editada por el propio Caramuel en la imprenta que fundó en Satriano, y está sufragada por él mismo.

${ }^{26}$ Para la edición y traducción, hemos tomado en cuenta la edición primera de la Rítmica, por su inferior volumen y porque la doctrina métrica es absolutamente la misma en ambos casos. 


\subsection{Estructura interna}

Nos la proporciona el propio Caramuel en la quinta página (sin numerar) de su Rhythmica : "Tomorum Liberalium Ordo":
(1). "Primus GRAMMATICA"
(2). "Secundus RHYTHMICA"
(3). "Tertius METAMETRICA"

La estructura interna, pues, no se corresponde con la externa. Podemos conjeturar que, en los pocos años que median entre la edición de la Metametrica y de la Rhythmica, el diseño intelectual del Primvs Calamvs se fue perfilando para el propio autor. En la misma página él justifica ante el lector la alteración, recurriendo a la imagen de la lente convexa. ${ }^{27}$

\section{3. La Gramática}

¿Dónde está la "Gramática"?, podemos preguntarnos. Fundamentalmente, en un libro independiente y anterior, ya mencionado: la Gramática audaz (1651), así como en el Prcecursor Logicus complectens Grammaticam Audacem (1654).

Pero también está la Gramática en el "PRODROMVS METAMETRICVS" con que comienza la Metametrica. ${ }^{28}$ Abarca las páginas j-xxxij ( $\S 22-53)$. Expone en ellas, de manera sintética y racional, primero los fundamentos de las gramáticas castellana e italiana -emparejadas en cada página, a doble columna, y expresadas en las respectivas lenguas-; y después la gramática latina, en latín. Le sigue, a modo de ejercicio académico, un texto, «Ad Lavdem B. Francisci Salesii, Panegyris» (xxxiij-

${ }^{27}$ He aquí la traducción de la profesora Avelina Carrera: «Las lentes, si son convexas, invierten los rayos y cambian a la izquierda lo de la derecha y lo primero lo ponen lo último. De este tipo son mis lentes, pues, mientras trabajo con pocos caracteres y me adapto al tiempo, forzosamente cambio el orden, porque lo que más pronto se concibió, más tarde se da a la luz, y sin embargo es lo primero que ha de leerse».

${ }^{28}$ Después de las habituales páginas que contienen la dedicatoria del libro y poemas encomiásticos de amigos -en este caso, en varias lenguas-, encontramos un poema latino del autor a sus condicípulos, y una carta al lector sobre los estudios humanísticos. 
xxxiij) ( $\S 54-60)$, en cuyo margen derecho va anotando comentarios eruditos y reglas gramaticales.

\subsection{La Metametrica}

Se ocupa de la Poética o principios teóricos de una poesía singular: la barroca en lengua latina, que se desarrollaba en la Europa del siglo XVII. Este enfoque supranacional, esta asombrosa amplitud de miras, sólo es posible en la pluma de un hombre como Caramuel, marcado desde su nacimiento por el cosmopolitismo, y que desarrolló una activísima existencia en diversos países. En sus propias palabras:

Artem hanc, quam veteres Musæ non docent, quam nescit antiquus Parnassus, vltra Parnassum, \& Scientiam Metricam reperi, $\&$ ideò Metametricam vocari volui; \& quia est ditissima, \& copiosissima, per vlteriora tempe distributam Apollinibus diuersis consecraui. Vnum tantùm venerati sunt Veteres; at nos in vlterioribus Elisijs, triginta, vel plures inuenimus.

Este libro, que da cuenta de formas poéticas del siglo XVII -tanto españolas como europeas- en lengua latina (laberintos, acrósticos, ecos, esteganografías, etc.) merecería sin duda también una traducción y un amplio estudio.

Se ha acusado a la Metametrica de oscuridad y desorden. No lo vemos así. Por el contrario, su exposición nos parece ordenada y clara, siempre que nos hagamos con las claves intelectuales del libro y nos situemos en la época barroca. El propio Caramuel se anticipa a las críticas:

Respondeò Metametricam nostram esse perviam \& facilem, vtvt sit difficilis, quid inde? ideò illa dignior, vt à sublimibus ingeniis pertractetur. [...] Ergo, si sit nostra Metametrica difficilis, obscura, impervia, animos generosos ipsamet invitabit obscuritas, \& brevi tempore cedet labori \& studio, eritque clara. ${ }^{29}$

${ }^{29}$ Matametrica, II (§ DLXXVIII). 
Parafraseando a Gracián, podríamos decir que la "agudeza y arte de ingenio" para la Métrica encuentra su culminación en la Metametrica de Caramuel.

El diseño global del Primvs Calamvs, con las tres partes de Gramática, Metamétrica y Rítmica, nos parece, así, mucho más nítido y ordenado de lo que se ha venido diciendo: En la Metametrica encontramos, además de la inicial Gramática comparada (latina-española-italiana), que se basa en principios universales, sencillos y perfectamente lógicos, una Métrica latina comparada (con la española, sobre todo, y con otras: hebrea, italiana, francesa, etc., todo ello en pinceladas). En la Rhythmica, en cambio, Caramuel se centrará en la versificación de las lenguas modernas, especialmente la española, de la cual hará un tratamiento exhaustivo.

\section{La Rhythmica}

Siguiendo la oposición medieval y renacentista entre "Métrica" (estudio de la poesía escrita según las reglas de las lenguas griega y latina, regidas por la cantidad silábica) y "Rítmica" (estudio de la poesía escrita en las lenguas neolatinas y modernas, regidas por el acento), Caramuel establece una neta oposición entre ambas, produciendo dos libros diferentes de la materia que hoy denominamos unívocamente "Métrica". He aquí sus palabras:

Rhythmica, \& Metrica facultates sunt duæ: illa omnibus populis communis, hæc Græcorum, \& Latinorum propria: illa accentus, ista quantitates considerat. ${ }^{30}$

En la Rhythmica, pues, va a estudiar los sistemas métricos regido por el acento. Se trata de un planteamiento general, abstracto: el conjunto de posibilidades del lenguaje versal. Su ejemplificación la realizará fundamentalmente mediante la poesía

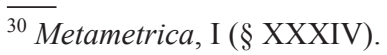


en lengua española, tomando como modelos a poetas como Góngora, el Príncipe de Esquilache, Quevedo, Garcilaso, Jerónimo de Cáncer, Lope de Vega, etc. Pero no se limitará a la literatura española en verso, sino que, viviendo en Italia cuando escribe estos libros, constantemente estará mirando a la literatura italiana, de la cual aporta numerosos ejemplos. También mira a la literatura francesa, y a otras europeas (húngara, alemana, neerlandesa, etc.), e incluso orientales (siria, árabe, hebrea, japonesa, china, ${ }^{31}$ etc.)

La Rhythmica, al igual que la Metametrica, es un libro didáctico. Constantemente tiene presente a un lector ideal, poeta y joven, al que llama "Filomuso" -amante de las Musas-. A él le dirige sus exposiciones, se anticipa a sus dudas y resuelve sus hipotéticas preguntas.

Como libro didáctico - aunque no para todos, sino para unos pocos, e incluso para uno solo-, 32 contiene una excelente "Synopsis" al comienzo del "Liber Primvs", p. 18, y un cuadro sinóptico al comienzar el "Liber Secvndus", p. 52. Sin embargo, en la primera edición no tiene un Indice que nos vaya orientando sobre la totalidad del libro (Esto lo subsanará en la segunda edición).

Para una mejor comprensión del conjunto, vamos a exponer sucintamente sus contenidos, con el fin de abarcar su amplitud conceptual.

${ }^{31}$ Caramuel es autor también de una Grammatica Sinensis.

32 Esto lo explicita en la Dedicatoria del libro a D. Sebastián López Yerro de Castro. En traducción de la profesora Carrera: «Escribo para pocos, a veces para uno o para otro, e incluso para mí solo o para nadie. [...] Si quieres que algo guste, hazlo raro. [...] La segunda parte de este Primer Cálamo, para que les guste a unos cuantos, no la voy a ofrecer a todos, sino a uno solo. [...] Hay que escribir para los amigos, no para los adversarios». 


\subsection{Las Epístolas}

Constituyen el núcleo de la Poética o Teoría literaria de Caramuel. De ahí su importancia. ${ }^{33}$ Siguiendo de manera libre la pauta de las Poéticas del "Cinquecento" italiano -y de modo especial la de Escalígero, que nuestro autor cita a menudo en su Metametrica-, realiza en las ocho Epístolas iniciales una apretada síntesis de la poesía universal y de la española, se plantea el canon poético para su imitación, sitúa en la "ficcionalidad" -diríamos hoy- o en el "fingir" -como dice Caramuel- la raíz de lo literario (en un preanuncio de las más recientes teorías), y salva las distancias entre Teología y Poética.

En cuanto a las siete Epístolas finales -que cierran circularmente el libro y van dirigidas en su mayoría a personas concretas-, retoman el tema último, añadiendo que no sólo los intelectuales y nobles deben aprender Poética, sino también las clases desfavorecidas. Además, aborda cuestiones puntuales: comenta un libro métrico de Girolamo Ruscelli, realiza una comparación entre la métrica italiana y la latina, etc.

\subsection{Los tres "Libri"}

Entre un bloque y otro de Epístolas, se sitúa la mayor parte de la Rhythmica (pp. 18-407): su corpus doctrinal. Y lo hace articulándose en tres partes o "libri".

El "Liber Primvs" va a tratar "de Literis, Figvris, et Tonis", es decir, de la consideración métrica de las letras, ya que la letra es "la parte mínima del poema". Así opinará, p. ej., que la rima se apoya en el sonido y no en la grafía: "bebe"-"mueve"); estudiará las "figuras" o fenómenos métrico-gramaticales (sinalefa, diéresis, elipsis, etc.); y también los "tonos" ("de accentu et concentu"), es decir, la acentuación de las palabras en el verso, y la rima o "concento", cuyas especies, afirma Caramuel, son: la

${ }^{33}$ Ha motivado la traducción independiente de las primeras siete Epístolas (de las ocho existentes), y su comentario por parte del profesor Hernández Nieto (1992). También el prologuista de este libro, el profesor Alberto Porqueras Mayo, habla con admiración de ellas.

Sobre las epístolas renacentistas véase: Grupo P.A.S.O.: La epístola (2000). 
asonancia, la consonancia, la equisonancia, la unisonancia y la disonancia (o carencia de rima). ${ }^{34}$ En todos estos temas muestra el obispo madrileño su profunda originalidad e independencia de juicio. ${ }^{35}$

El "Liber Secvndus" (pp. 52-407) es la parte más extensa y nuclear. Dividido en ocho capítulos, establece tres criterios clasificatorios para los versos: $1^{\circ}$ ) Considerando el verso aislado, hay que tener en cuenta su naturaleza oxítona, paroxítona o proparoxítona, así como el número de sílabas hasta el último acento. $2^{\circ}$ ) Considerando el verso en su relación con otro, hay que atender a la rima (asonante, consonante o disonante). Y $3^{\circ}$ ): Considerando el verso agrupado con otros, encontramos las diversas estrofas (Dísticos, Tetrásticos, etc.)

Puesto que estamos en Sevilla, donde el Profesor Esteban Torre viene sosteniendo desde hace años en sus libros ${ }^{36}$ que el verso debe contar solamente hasta la última sílaba acentuada, la que lleva el acento versal, tenemos que resaltar este precedente: Para Caramuel tiene tanta importancia el último acento versal, que lo tomará como criterio para nombrar los metros: el "Trisyllabo" será el verso de 4 sílabas, cuyo acento último está en la tercera; "Heptasyllabo" el de 8; etc. Desinteresándose de la sílaba postónica, átona, final de verso, Caramuel se aparta de la tradición española e italiana, y, siguiendo sus propias ideas, se adhiere a la tradición provenzal, francesa y portuguesa, que computan de este mismo modo.

Capítulo importante es el segundo, donde analiza todos los que hoy llamamos metros, desde el "Trisílabo" (tetrasílabo)

${ }^{34}$ En realidad, los tres tipos fundamentales de rima son para Caramuel -como hoy en día- la asonancia, la consonancia y la carencia de rima, que él llama, como Rengifo, disonancia. Equisonancia y asonancia son dos modalidades -"especies"- poco frecuentes, de palabra que rima consigo misma. Bien conservando el mismo significado (la "unisonancia"), bien con modificación del significado (la "equisonancia"). De todos los tipos de rima aporta abundantes ejemplos.

${ }^{35}$ Por ejemplo, cuando se pregunta si en los versos heroicos [endecasílabos sueltos] los versos agudos deben ser condenados. Frente a la opinión común, que los rechaza, él los admite, sobre la base de diversos poemas de Petrarca y Lope de Vega.

${ }^{36}$ Esteban Torre (El ritmo del verso, 1999: 51-77, y Métrica española comparada, 2000: 40). 
hasta el "Deca-tetrasílabo" (el de 16 sílabas, compuesto). Él los denomina «variis generibus carminum, ex syllabarum numero». Igualmente se plantea la posibilidad de los versos Monosílabos y Bisílabos (2 y 3 sílabas, respectivamente), aunque él afirme no haberlos visto más que raramente en italiano. Opina que pueden existir si están bien hechos.

(Como podemos observar, una característica de la Rítmica de Caramuel es que no solamente describe los tipos métricos que él conoce porque los poetas los han usado, sino que también plantea los posibles, las casillas vacías del sistema -diríamosque pueden llegar a actualizarse. Su espíritu matemático, científico, le induce a ello).

Al final de este segundo capítulo examina una forma métrica muy española, la Seguidilla (lat. "Secundina" y "Consectaria"). El capítulo III se centra en los tipos de versos asonantes ("De versuum assonantium generibus"), y estudia otra forma específicamente hispana: el Romance -con sus derivaciones, como la Jácara-.

Muy importante es el examen de las estrofas posibles -y las españolas en particular-, que ocupa todo el capítulo IV. Tomando como criterio el que hoy día impera, el número de versos en cada estrofa, abarcará desde los "Dísticos" hasta los "Decásticos" (décimas), dedicando incluso unas líneas a los escasos experimentos que se han realizado mezclando ordenadamente estrofas de dos tipos ("Polísticos").

Y estudiará no sólo las estrofas con versos de un mismo número de sílabas -las que hoy llamamos isométricas-, sino también las estrofas con versos "scissi" o quebrados -las heterométricas-. Al tener Caramuel en cuenta tantos elementos, la tipología de cada elemento que estudia se amplía extraordinariamente. Por ejemplo, en el estudio de los tercetos encadenados ("Tristichi"), encuentra 4 tipos ("genera") según la disposición de la rima, cada uno de los cuales tiene en el poema un modo de cierre ("clausula") determinado. Helos aquí: 
Genus I. ABA.BCB.CDC.DED.EFE. \&c. Clausula. FGG. vel FGFG. vel FGHFGH.

Genus II. ABC.BCD.CDE.DEF.EFG. \&c. Clausula. FGG. vel FGFG. vel FGHGH.

Genus III. ABC.CAD.DCE.EDF. \&c. Clausula. FEE. vel FEFE. vel FEHEH.

Genus IV. ABC.CBD.DBE.EBF. \&c. Clausula. FBB. vel FBGG. vvel FBHBH.

Sumo interés en este Libro Segundo suscitan los capítulos V, VI, VII y VIII, donde Caramuel examina los grandes tipos poemáticos de origen italiano: la Canción, la Lira y el Soneto.

La canción contaba con una gloriosa tradición de estudios en Italia: En primer lugar, reflexionó sobre ella Dante, en su De Vulgari Eloquentia (escrito alrededor de 1304, pero publicado solamente en 1529). ${ }^{37}$ Caramuel no parece conocer este tratado, pues no lo cita. En segundo lugar, Antonio da Tempo -el cual tampoco había podido leer el libro de Dante-, teoriza sobre la "cantio", y tanto Rengifo como Caramuel tienen muy presente su obra: Summa Artis Rithimici Vulgaris Dictaminis, 1332. ${ }^{38}$ También había sido la canción cuidadosamente estudiada en España por Juan Díaz Rengifo en su Arte Poética Española (1592). ${ }^{39}$ Observando la práctica de Petrarca, Rengifo enumera 29 tipos de canción. Caramuel se basa en este autor, pero también en el portugués Miguel Sánchez de Lima (en El Arte Poética en Romance Castellano, 1580), ${ }^{40}$ el cual considera que la canción como forma sólo depende de la voluntad del poeta, no de los modelos.

\footnotetext{
${ }^{37}$ Dante Alighieri: De Vulgari Eloquentia. Milano, Signorelli, 1988.

${ }^{38}$ Antonio da Tempo $(1332 ; 1977)$.

39 Juan Díaz Rengifo (1606, 1977).

${ }^{40}$ Miguel Sánchez de Lima (1580, 1944).
} 
El capítulo sobre la canción en Caramuel, el V (pp. 245-333) es uno de los más nutridos y complejos del libro. No sólo se ocupa de la canción que hoy llamamos "de estancias", de su origen, de la polémica sobre su libertad o no, incluso de su música ("De Cantione Musicâ"), sino que enumera en los dieciocho "Articuli" o Apartados los diferentes tipos contemporáneos de canción en España e Italia.

Por suerte o desgracia, mezcla Caramuel en el mismo estudio dos tipos de canción que tienen origen distinto: la canción horaciana -que se plasma en estrofas aliradas y carece de cierre-, y la canción de estancias -que usa estrofas más largas y tiene cierre o "envío"-. En todo caso, esto es algo fácilmente salvable, $\mathrm{y}$ es de agradecer el esfuerzo descriptivo de nuestro autor. (Por otra parte, el deslinde entre formas aliradas extensas y canciones de estancias con estrofas de pocos versos sigue siendo un tema aún discutido en nuestros días). ${ }^{41}$

Con la valentía y decisión que le caracterizan, no duda Caramuel en abordar, en el artículo final de la canción, uno de los temas más espinosos, que llega incluso hasta hoy: la frontera entre tres formas muy próximas: la canción [que hoy llamamos de estancias], la silva y el madrigal. Lo hace nuestro autor en "De Carmine dicitur Hisp. Madrigal; \& an quomodo differat à Cantione \& Sylvâ?"

Comenzando por el origen de la palabra "Madrigal", se aparta de la opinión de Rengifo ${ }^{42}$ y se apoya en Pietro Bembo, para quien la palabra deriva de "Materialis". Respecto a las tres reglas del madrigal ( $1^{\mathrm{a}}$ : que contenga 12 versos o menos; $2^{\mathrm{a}}$ : que las consonancias vayan agrupadas de dos en dos -AA.BB.CC., etc.-; $3^{\text {a }}$ : que no tenga varias estrofas), rechaza la primera y la segunda sobre la base de ejemplos de Góngora y Esquilache. Por el contrario, admite la tercera. Y concluye que si el poema tiene diversas estrofas, es Canción. Si no está dividido en estrofas uniformes, y tiene 20 versos o menos, se llama Madrigal. Y si tiene más de 20 versos y no tiene estrofas, es Silva.

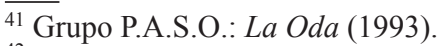

42 Este autor, concorde con Antonio da Tempo, derivaba la palabra de "Mandra": 'cabaña de pastor o aprisco de ovejas'.
} 
A continuación, estudia otro tipo de canción -ya diferenciada en Rengifo-: la Sextina. El capítulo VI, que trata de ella, es clara muestra del proceder intelectual de Caramuel: Estudia la sextina de Arnaut Daniel a fondo, incluso en sus valoraciones ("An Sextina sit Compositionum omnium excellentissima? An sit Cantio?"). Pero además estudia los tipos modernos de sextinas ("De novo quodam genere Sextinarum"), y no sólo los que se han escrito, sino incluso los posibles: Conservando la retrogradación característica de la sextina así como sus palabras-rima, usarla con estrofas de 5 versos, o de 4 , o de 3 o de 2, y también en agrupaciones mayores: de 7 versos, o de 8.

En el capítulo VII, "De Lyris", analiza no sólo la lira de 5 versos -ya estudiada por Rengifo-, sino también la de 6, lo cual es novedad en la teorización métrica. Además, otra novedad: reseñar sus "modi" o combinaciones de rimas, e incluso sus distintos ritmos. Y atento siempre a las futuras expansiones de los esquemas poemáticos, se plantea la existencia posible de liras con octosílabos y otros metros españoles.

Por último, el estudio del Soneto ocupa el capítulo VIII (pp. 375-407). Sigue en él la clasificación que realizaron Rengifo y Tempo, pero con un buen número de observaciones personales.

El "Liber Tertivs. De Sylvis" (pp. 408-512) contiene un diccionario de rimas. Su modelo sigue siendo Rengifo -cuya "Sylva de consonantes" era celebérrima-, pero Caramuel, que le sigue de cerca, añade elementos y reclasifica sus categorías.

Y cierran la Rhythmica las seis Epístolas mencionadas anteriormente.

\section{Conclusión: una métrica barroco-renacentista}

La Rhythmica tiene un claro antecedente, que venimos comentando: el Arte Poética Española, de Juan Díaz Rengifo (1592). Este libro magistral, modélico para todos los posteriores sobre la materia -como hemos mostrado en nuestro estudio (2000)-, ${ }^{43}$ es

${ }^{43}$ Isabel Paraíso: "Fundación del canon métrico: el Arte Poética Española, de Juan Díaz Rengifo (1592)”. En: I. Paraíso (ed.), 2000: 47-93. 
citado muy a menudo y con admiración por Caramuel. (Lo cual no le impide discrepar de él en contadas ocasiones, alguna de las cuales ya hemos visto). Incluso las dos fuentes más importantes de Rengifo, Antonio da Tempo (Summa Artis Rithimici Vulgaris Dictaminis, 1332) y Girolamo Ruscelli (Del modo di comporre $i$ versi nella lingua italiana, 1559), son también consultadas y comentadas por Caramuel en esta obra. De los esquemas gráficos que Rengifo inserta en su obra puede haber tomado el concepto de "idea" métrica, que en Caramuel resulta clave:

Ideâ Metrica differt à Carmine, sicut vniuersale à singulari. ${ }^{44}$

La comparación entre Rengifo y Caramuel, los dos grandes teóricos de la métrica española, es ya un "topos" en nuestros estudios. Señalemos solamente la preferencia de Marcelino Menéndez y Pelayo por Caramuel: «Por la riqueza material de metros y combinaciones, le vence [al Arte Poética Española] la Rítmica de Caramuel, que bajo este aspecto es un verdadero mundo prosódico» ${ }^{45}$

Si tuviéramos que destacar las cualidades máximas de este libro -o del pensamiento de Caramuel-, tendríamos que hablar de su originalidad, su modernidad y su sistematismo. Dotado de una mente privilegiada, Juan de Caramuel Lobkowitz se atreve siempre a superar los límites establecidos. Su criterio ante los problemas es siempre la verdad, no la autoridad. De ahí lo estimulantes y originales que resultan sus escritos.

En la misma dirección va su modernidad: Gran conocedor de la cultura clásica, se interesa por lo que se está haciendo en el presente, y lo estudia de manera experimental, concreta. Además, para poder abarcar tantas ciencias, necesita un gran orden mental.

${ }^{44}$ Metametrica, II, (§ 611). Por "Ideâ" (métrica o rítmica, según esté tratando de poemas latinos o españoles) entiende el esquema abstracto de un poema: estrofa, metro, etc. En cambio, "Carmen" es la realización concreta de alguna "idea". Véase también, en Metametrica, I ( $\S$ V y VII), "Quid sit Ideâ? quid Carmen? an debeant res diuersa confundi?"

Nótese cómo Caramuel se anticipa en dos siglos y medio a los formalistas rusos sobre este punto del "modelo" y la "ejecución" del poema.

${ }^{45}$ Historia de las Ideas Estététicas en España, cit., vol. I: 695. 
El sistematismo con que aborda cada cuestión hace que ésta se sitúe exactamente en un punto preciso del conjunto de saberes, $y$ desde allí pueda relacionarse con los restantes.

La Rhythmica de Juan Caramuel destaca, entre todos los libros de Poética y Métrica, por la amplitud de sus miras, por la valentía de sus planteamientos, y por la exactitud de sus observaciones.

\section{Bibliografía}

ALIGHIERI, Dante: De Vulgari Eloquentia. Milano, Signorelli, 1988.

BORREGO HERNÁNDEZ, Nicolás: "Aportaciones de Caramuel a la lógica teórica". Cuadernos Salmantinos de Filosofía, 19, 1992: 363-399

—: "La lógica oblicua de Caramuel". Theoria, VII, 1992: 298.

CARAMUEL, Juan de: Primvs Calamvs, t. I: Metametrica, 2 vols. Roma, Fabius Falconius, 1653.

-: Primvs Calamvs, t. II: Rhythmica. Sanctvm Angelvm della Fratta, Ex Typographia Episcopali Satrianensi, 1665.

-: Primvs Calamvs, t. II: Rhythmica. Editio secunda. Campaniæ, Ex Officina Episcopali, 1668.

(Esta "segunda edición" en realidad es reedición idéntica del corpus doctrinal de la primera, al que se le añaden índices en las páginas del principio, y nuevas epístolas finales. El propio Caramuel en el frontispicio de esta edición la comenta así: "Diversis, iisque necessariis Indicibus locupletata").

-: Syntagma de Arte Typografica. Edición, traducción y glosa de Pablo Andrés Escapa. Salamanca, Instituto de Historia del Libro y de la Lectura, 2004, 240 pp.

-: Gramática audaz. Trad. de Pedro Arias; estudio preliminar de Lorenzo Velázquez. Pamplona, EUNSA, 2000.

-: Pracursor Logicus complectens Grammaticam Audacem.. Stuttgart-Bad Cannstatt, Frommann-Holzborg, 1989.

—: Laberintos. Ed. de Víctor Infantes. Madrid, Visor, 1981.

-: Syntagma de Arte Typographica. Traducción y edición de Pablo Andrés Escapa. Salamanca, Instituto de Historia del Libro y de la Lectura, 2004.

-: Arquitectura civil recta y oblicua, 3 vols. Edición facsímil. Estudio preliminar de Antonio Bonet Correa. Madrid, Turner, 1984.

-: Filosofía de la Matemática. Estudio preliminar y traducción de Juan Velarde Lombraña. Barcelona, Alta Fulla, 1989.

DIETRICK, Déborah: "La Sylva de Consonantes de Juan Díaz Rengifo (1606) y el Liber Tertius, de Sylvis de Juan Caramuel (1665)". Próxima publicación en el Homenaje al Profesor Antonio Quilis. Madrid, U.N.E.D., 2004. 
DÍEZ ECHARRI, Emiliano:Teorías métricas del Siglo de Oro. Madrid, Consejo Superior de Investigaciones Científicas, Revista de Filología Española, 1949; 2ª ed. 1970: 87-88.

FARTOS MARTÍNEZ, Maximiliano: La filosofía española en Castilla y León; cap. "Caramuel". Universidad de Valladolid, 1997: 503-511.

GRUPO P.A.S.O.: La Oda. Ed. Begoña López Bueno. Universidad de Sevilla, 1993. - La epistola. Ed. Begoña López Bueno. Universidad de Sevilla, 2000.

HERNÁNDEZ NIETO, Héctor: Las ideas literarias de Caramuel. Barcelona, PPU, 1992.

LÓPEZ PIÑERO, José María: Ciencia y técnica en la sociedad española de los siglos XVI y XVII. Barcelona, Labor, 1979.

MENÉNDEZ Y PELAYO, Marcelino: Historia de las Ideas Estététicas en España. Madrid, C.S.I.C., 1974, 2 vols. Sobre Caramuel, en vol. I: 695 y 798-801.

PARAIÍSO, Isabel: "Fundación del canon métrico: el Arte Poética Española, de Juan Díaz Rengifo (1592)”. En: I. Paraíso (ed.): Retóricas y Poéticas españolas. Siglos XVI-XIX. Universidad de Valladolid, 2000: 47-93.

-: "La teoría de la glosa (o "carmen regium) en Rengifo y Caramuel". Próxima aparición en el Homenaje a la Profesora María del Carmen Bobes. Madrid, C.S.I.C. - Universidad de Oviedo.

PORQUERAS MAYO, Alberto: "Prólogo" al citado libro de Héctor Hernández Nieto (1992).

RENGIFO, Juan Díaz (Diego García): Arte Poética Española. Ministerio de Educación y Ciencia, edición facsímil de la segunda edición (1606), 1977.

SÁNCHEZ DE LIMA, Miguel: El Arte Poética en Romance Castellano. Madrid, C.S.I.C. Al cuidado de Rafael de Balbín, 1944.

TADISI, Jacopo Antonio: Memorie della vita di Monsignore Giovanni Caramuel di Lobkowitz, Vescovo di Vigevano. Venezia, 1760.

TEMPO, Antonio da: Summa Artis Rithimici Vulgaris Dictaminis. A cura di Richard Andrews. Bologna, Commisione per i Testi di Lingua, 1977.

TORRE, Esteban: El ritmo del verso. Universidad de Murcia, 1999. -: Métrica española comparada. Universidad de Sevilla, 2000.

VELARDE LOMBRAÑA, Julián: Juan Caramuel. Vida y obra. Oviedo, Pentalfa Ediciones, 1989. 